\title{
DERIVATIVES OF 16-MEMBERED MACROCYCLIC LACTONES: ANTIPARASITIC PROPERTIES AND INTERACTION WITH GABA RECEPTORS
}

\section{M.Kh. DZHAFAROV', F.I. VASILEVICH' ${ }^{1}$, G.I. KOVALEV ${ }^{1,}$, , K.S. KRIVONOS', I.I. TSEPILOVA' ${ }^{1}$ I.V. ZAVARZIN ${ }^{3}$, E.V. VASIL'EVA ${ }^{2}$}

\begin{abstract}
${ }^{1}$ Moscow State Academy of Veterinary Medicine and Biotechnology-K.I. Skryabin Moscow Veterinary Academy, 23, ul. Akademika Skryabina, Moscow, 109472 Russia, e-mail mxd123@mail.ru;

${ }^{2}$ V.V. Zakusov Research Institute of Pharmacology, Federal Agency of Scientific Organizations, 8, ul. Baltiiskaya, Moscow, 125315 Russia, e-mail kovalev@academpharm.ru;

${ }^{3}$ N.D. Zelinsky Institute of Organic Chemistry, Federal Agency of Scientific Organizations, 47, Leninskii prosp., 119991 Russia, e-mail zavi@ioc.ac.ru
\end{abstract}

Acknowledgements:

Supported by Russian Science Foundation, grant № 15-16-00019

Received June 8, 2016

\section{Abstract}

Searching for antiparasitics with a different mode of action than existing drugs, and (or) with the same but much more effective mechanisms is necessary to periodically update the applicable protection chemicals. For the first time we here present data on the biocidal action of new semisynthetic derivatives of avermectin B1 that we have synthetized earlier. These are the 16-membered macrocyclic lactones, the representatives of an important class of anthelmintics. In $2015 \mathrm{~S}$. Omura (Japan) and W. Campbell (USA) who discovered this avermectin group, were awarded the Nobel Prize in physiology and medicine. In our study the oligochaetes Tubificidal tubifex were used as a test-object. The original chemicals and synthetized derivatives tested were avermectin B1 (abamectin), ivermectin, monosaccharide analogues of abamectin and ivermectin, namely abamectin, ivermectin, 5-O-succinyl avermectin B1, methyl ester of 5-O-succinyl avermectin B1, ethyl ester of 5-O-succinyl avermectin B1, diethyl ester of 5,4"-di-O-succinyl avermectin B1, ethyl ester of 5-Omalonyl avermectin B1, diethyl ester of 5,4"-di-O-dimalonyl avermectin B1, monosaccharide hemisuccinate of avermectin B1 (5-O-succinyl-4'-dezoleandrozyl-4'-hydroxyavermectin B1), ethyl ester of 5-O-succinyl-4-O-chloroacetyl avermectin B1, 5-O-succinyl ivermectin, ethyl ester of 5-O-succinoyl ivermectin, 5,4"-di-O-succinyl ivermectin, diethyl ester of 5,4"-di-O-succinyl-ivermectin, ethyl ester of 5-O-malonylivermectin, diethyl ester of 5,4"-di-O-dimalonyl ivermectin, monoavermectin-5-yl ester of 4-[2-(4-nitrophenyl)-2-oxoethoxy]-4-oxobutanoic acid, monoavermectin-5-yl ester of 4-[2-(4-chlorophenyl)-2-oxoethoxy]-4-oxobutanoic acid, monoavermectin-5-yl ester of 4-[(4-nitrophenyl)-methoxy]-butanoic acid, monoavermectin-5-yl ester of 4-[1-methyl-2-(4-methylphenyl)2-oxoethoxy]-4-oxobutanoic acid, monoavermectin-5-yl ester of 4-[2-(4-chlorophenyl)-1-methyl-2oxoethoxy]-4-oxobutanoic acid, monoavermectin-5-yl ester of 4-[3-chloro-1-(4-chlorbenzoil)-propoxy]-4-oxobutanoic acid, monoavermectin-5-yl ester of 4-\{2-[(4-methylphenyl)-amino]-2-oxoethoxy\}-4-oxobutanoic acid and monoavermectin-5-yl ester of 4-\{2-[(4-bromophenyl)-amino]-2-oxoethoxy\}-4-oxobutanoic acid. The acute toxicity $\left(\mathrm{LD}_{50}\right)$ of the most effective ones, 5-O-succinyl avermectin B1, 5-O-ethylsuccinyl avermectin B1 and 5,4"-di-O-ethylsuccinyl avermectin B1, for intraperitoneally challenged white mice was $37.85 ; 41.37$ and $45.82 \mathrm{mg} / \mathrm{kg}$, respectively. We also used membrane preparations of rat brain as in vitro model for screening and studying activity of natural and semi-synthetic avermectins. A radioligand [G-3H]SR 95531 binding assay of avermectin B1, ivermectin, and 5-O-succinyl avermectin B1 interaction with GABA-receptors (the biotargets for these compounds) showed a $30 \%$ increase of maximal inhibition (Imax) of specific binding by hemisuccinate derivative of avermectin B1 when compared to original avermectin B1.

Keywords: 16-membered macrocyclic lactones, avermectins, avermectin monosaccharides, 5-O-succinyl avermectin B1, 5-O-ethylsuccinyl avermectin B1, 5,4"-di-O-ethylsuccinyl avermectin B1, antiparasitics, oligochaeta Tubifex tubifex, $\mathrm{GABA}_{\mathrm{A}}$-receptor, radioligand binding assay

Chemotherapy and prophylaxis remain among the most effective and cheap methods of controlling parasites. The most important classes of anthelmintics are benzimidazoles, imidazoles and thiazoles, pyrazine isoquinolines, 
macrocyclic lactones [1], especially 16-membered macrocyclic lactones with a broad spectrum of the antiparasitic activity. Adaptation of parasites (the development of resistance) to the applied aagents, and focus on high-performance and environmentally safer remedies promote the search for substances with both a novel mechanism of antiparasitic action and a known, but more effective one [2].

The 16-membered macrocyclic lactones (avermectins and other, similar in structure, natural macrolides called milbemycins or their semi-synthetic analogues) are widely used to control parasites (nematodes, insects and mites) in humans, animals and plants. For the discoveries of a novel avermectin-based therapy of infections caused by roundworm parasites, S. Omura (Japan) and W. Campbell (USA) were awarded 2015 Nobel Prize in Physiology or Medicine [3].

Evolution of pharmaceutical substances based on macrocyclic lactones suggests in particular the chemical modification of the natural metabolites and derivation of analogues that are the most suitable for practical purposes (Fig. 1) $[4-8]$.

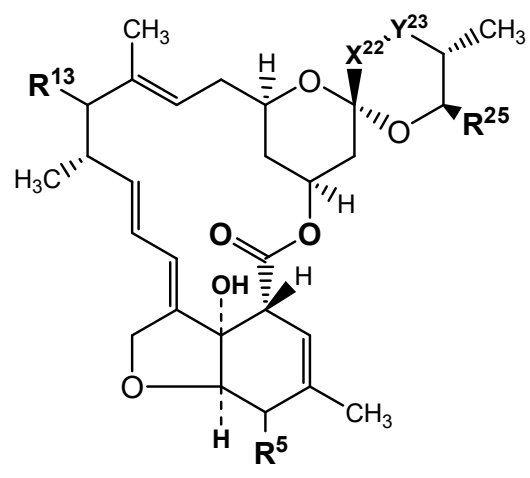

Fig. 1. The general formula of natural and semi-synthetic avermectins: $\mathrm{R}^{5}-$ a hydroxyl group or a modified functional group; $\mathrm{R}^{13}$ - L-oleandrosyl-L-oleandroside residue; $\mathrm{R}^{25}$ - various hydrocarbon radicals [2].

Various avermectins and related milbemycin-based substances have been introduced in the medical, veterinary and agronomic practices, such as a mixture of avermectin B1a and B1b (abamectin, 1979), ivermectin (1981), doramectin (1993), avermectin B1 benzoate (1997), eprinomectin (1997), and selamectin (2000), as well as close to them Milbemectin, a mixture of A3 (a3) and A4 (a4) milbemycins (1990), lepimectin (a derivative of milbemectin, 2004), a derivative of nemadectin (Moxidectin, 1989), and Gemax [2, 4]. Antiparasitic action of all these macrolides is due to the pharmacophore group, i.e. a unique 16-membered lactone [2], specifically interacting with glutamate- [9] and $\mathrm{GAB}_{\mathrm{A}}$-dependent $\mathrm{Cl}^{-}$-ion channels [10].

Most studies on the mechanism of avermectins' action, i.e. membrane hyperpolarization resulted from activation of glutamate- and $\mathrm{GABA}_{\mathrm{A}}$-dependent channels, were made with ivermectin, as the most frequent in practice [11-14]. In general, findings of such studies are applicable to all members of this class, although lactones are not similar in structure, and their effect may vary [15-17].

In the present study, we first report biocidal action of new semisynthetic avermectin B1 derivatives on oligochaetes. These findings allowed to select several promising compounds, such as 5-O-succinyl avermectin B1, 5O-ethylsuccinyl avermectin B1 and 5,4"-di-O-ethylsuccinyl avermectin B1. A decrease in toxicity $\left(\mathrm{LD}_{50}\right.$ of $37.85,41.37$ and $45.82 \mathrm{mg} / \mathrm{kg}$, respectively) was revealed compared to avermectin B1 (15-20 mg/kg) [18]. We compared avermectin B1, ivermectin and 5-O-succinyl avermectin B1 interaction with $\mathrm{GABA}_{\mathrm{A}}$-receptors, which are a biotarget for this class of compounds, using rat brain membrane preparations as a model for in vitro screening and evaluation of natural and semi-synthetic avermectins. It was revealed that maximal inhibition of specific binding for these synthesized derivatives, estimated by radioligand binding assay, increased.

The aim of this work was to study biocidal properties of the semi- 
synthetic derivatives of 16-membered macrocyclic lactones and their interaction with the $\mathrm{GABA}_{\mathrm{A}}$-receptors.

Technique. The 5-O- and 5,4"-di-O-derivatives of avermectin B1, ivermectin, and monosaccharide analogues have been previously synthesized [2, 19]. Their antiparasitic activity at a dose of $15 \mu \mathrm{g} / \mathrm{ml}$ was studied in a rapid assay using Tubifex tubifex oligochaetes. Acute toxicity of 5-O-succinyl-, 5-Oethylsuccinyl-, 5,4"-di-O-ethylsuccinyl avermectins B1 was determined according to the recommendations on preclinical studies of drugs using white outbred mice weighing 18-21 g (the drug was administered intraperitoneally) [20].

For the radioreceptor assay, avermectin B1, ivermectin and a hemisuccinate derivative of avermectin B1 were dissolved in dimethylsulfoxide (DMSO). In vitro effects of the substances on the $\mathrm{GABA}_{\mathrm{A}}$-receptors were investigated at the range of concentrations of $10^{-10}-10^{-4} \mathrm{~mol} / \mathrm{l}$.

Membrane preparations containing $\mathrm{GABA}_{\mathrm{A}}$-receptors of rat cerebral cortex were isolated by a modified method of J.E. Hawkinsonet al. [21]. Biomaterial was taken after decapitation. Frontal cortex was separated and homogenized (a Potter S homogenizer, Sartorius AG, Germany) in 20 volumes of ice-cold sucrose $(0.32 \mathrm{M}, \mathrm{pH} 7.1)$. A dense fraction was separated using the Optima L-70K ultracentrifuge (Beckman Coulter, Inc., USA) for $10 \mathrm{~min}$ at $1000 \mathrm{~g}$. The supernatant was re-centrifuged $(20000 \mathrm{~g}, 20 \mathrm{~min})$. The precipitate was resuspended in $20 \mathrm{ml}$ of cold distilled water and centrifuged $(8000 \mathrm{~g}$, $20 \mathrm{~min}$ ), the supernatant and the yellow supernatant were centrifuged once again at $48000 \mathrm{~g}$ for $20 \mathrm{~min}$. The precipitate was suspended in a freshly prepared $0.05 \mathrm{M}$ Tris-citrate buffer (TCB) ( $\mathrm{pH} 7.1$ ) and centrifuged (48 $000 \mathrm{~g}, 20$ $\mathrm{min})$. The resulting membrane fraction was frozen and stored at $-85^{\circ} \mathrm{C}$. On the day of testing, the membranes were suspended in 40 volumes of $0.05 \mathrm{M}$ TCB (pH 7.1) and centrifuged at $48000 \mathrm{~g}$ for $20 \mathrm{~min}$. The resulting precipitate was suspended in 40 volumes of $0.05 \mathrm{M}$ TCB $\left(\mathrm{pH} \mathrm{7.1)}\right.$, incubated at $24{ }^{\circ} \mathrm{C}$ for $30 \mathrm{~min}$, and centrifuged again at $48000 \mathrm{~g}$ for $20 \mathrm{~min}$. The final precipitate was resuspended in the fresh buffer.

Tritium-labeled [G- $\left.{ }^{3} \mathrm{H}\right] \mathrm{SR} 95531$ (Perkin Elmer, USA) with a specific activity of $49.5 \mathrm{Ci} / \mathrm{mmol}$ was used in radioligand binding assays. The incubation mixture $\left(0.5 \mathrm{ml}\right.$ final volume) contained $50 \mu \mathrm{l}$ of [G-3 $\left.{ }^{3} \mathrm{H}\right] \mathrm{SR} 5531,250 \mu \mathrm{l}$ of buffer and $200 \mu \mathrm{l}$ of membrane protein suspension; for non-specific binding, $50 \mu \mathrm{l}$ of unlabeled SR 95531 ligand $(1 \mathrm{mM})$ was added. The reaction mixture was incubated at $4{ }^{\circ} \mathrm{C}$ for 1 hour. After incubation samples were passed through the GF/B glass fiber filters (Whatman PLC, UK) previously immersed in $0.3 \%$ polyethylenimine for 2 hours. Each tube was washed twice with cold buffer and then the filters were washed twice with the same volume of buffer. The filters were dried out in air, transferred to scintillation vials and poured over with $5 \mathrm{ml}$ of scintillation liquid (4 g of PPO, $0.2 \mathrm{~g}$ of POPOP per liter of toluene). Radioactivity was determined on a Tri-Carb 2900TR counter (Perkin Elmer, USA) with 42-46\% counting efficiency. Specific binding was calculated as the difference between total and non-specific binding. The results of radioligand binding assay were expressed as the concentration corresponding to $50 \%$ inhibition of specific radioligand binding $\left(\mathrm{IC}_{50}\right)$ and the maximal degree of inhibition $\left(\mathrm{I}_{\max }\right)$, reflecting the difference between the lower and upper plateau [21]. Protein concentration was measured by a standard procedure [22].

Animal experiments were performed in accordance with the provisions of the Geneva Convention and the principles of Good Laboratory Practice (National Standard of the Russian Federation, GOST R 53434-2009), as well as recommendations set out in The Guide for the Care and Use of Laboratory Animals (Na- 
tional Academy Press Washington, DC 1996).

GraphPad Prizm 4 Demo (https://www.graphpad.com, GraphPad Software,

Inc., USA) was used to process binding displacement curves. Statistical processing was performed using Statistica 6 software package (http://www.statsoft.ru, Statsoft Inc., USA). The arithmetic mean $(m)$ and standard error of the mean (SEM) are given, the significance of differences was assessed by the Student's $t$-test at $\mathrm{p}<0.05$.

Results. We examined the biological effects of the synthesized 5-O- and 5-O-4"-O-derivatives as well as ivermectin and a number of monosaccharide analogues derived previously (Table 1).

\section{A qualitative comparison of the biocidal action of the derived 16-membered lac-} tones (concentration of $15 \mu \mathrm{g} / \mathrm{ml}$ ) on Tubifex tubifex oligochaetes

\begin{tabular}{|c|c|c|c|}
\hline \multirow{2}{*}{ Substance } & \multicolumn{3}{|c|}{ Time, $\min$} \\
\hline & 30 & 60 & 180 \\
\hline Abamectin (control) & +++ & ++++ & ++++ \\
\hline Ivermectin & +++ & ++++ & ++++ \\
\hline Tap water (control) & 0 & 0 & 0 \\
\hline Tap water:isopropanol 9:1 (control) & 0 & 0 & 0 \\
\hline 5-O-succinyl avermectin B1 & ++ & +++ & ++++ \\
\hline Methyl ester of 5-O-succinyl avermectin B1 & ++ & +++ & ++++ \\
\hline Ethyl ester of 5-O-succinyl avermectin B1 & ++ & +++ & ++++ \\
\hline Diethyl ester of 5,4"-di-O-succinyl avermectin B1 & ++ & +++ & ++++ \\
\hline Ethyl ester of 5-O-Malonyl avermectin B1 & ++ & +++ & ++++ \\
\hline Diethyl ester of 5,4"-di-O-Dimalonate avermectin B1 & ++ & +++ & ++++ \\
\hline Hemisuccinate derivative of avermectin B1 monosaccharide (5-O-succinyl-4'-Desoleandrosyl & & & \\
\hline 4'-Hydroxy avermectin B1) & ++ & +++ & ++++ \\
\hline Ethyl ester of 5-O-Hemisuccinyl-4"-O-Chloroacetyl avermectin B1 & ++ & +++ & ++++ \\
\hline $5-\mathrm{O}-$ Hemisuccinate ivermectin & ++ & +++ & ++++ \\
\hline Ethyl ester of 5-O-Hemisuccinate ivermectin & ++ & +++ & ++++ \\
\hline 5,4"-di-O-succinyl ivermectin & ++ & +++ & ++++ \\
\hline Diethyl ester of 5,4"-di-O-succinyl ivermectin & ++ & +++ & ++++ \\
\hline Ethyl ester of 5-O-Malonyl ivermectin & ++ & +++ & ++++ \\
\hline Diethyl ester of 5,4"-di-O-Malonyl ivermectin & ++ & +++ & ++++ \\
\hline Monoavermectin-5-yl ester 4-[2-(4-Nitrophenyl)-2-oxoethoxy]-4-oxobutanoic acid & ++ & +++ & ++++ \\
\hline Monoavermectin-5-yl ester 4-[2-(4-Chlorophenyl)-2-oxoethoxy]-4-oxobutanoic acid & +++ & +++ & ++++ \\
\hline Monoavermectin-5-yl ester 4-[(4-Nitrobenzyl)-methoxy]-4-oxobutanoic acid & ++ & +++ & ++++ \\
\hline Monoavermectin-5-yl ester 4-[1-methyl-2-(4-Methylphenyl)-2-oxoethoxy]-4-oxobutanoic acid & ++ & +++ & ++++ \\
\hline Monoavermectin-5-yl ester 4-[2-(4-chorophenyl)-1-methyl-2-oxoethoxy]-4-oxobutanoic acid & ++ & +++ & ++++ \\
\hline Monoavermectin-5-yl ester 4-[3-chloro-1-(4-chlorobenzoyl)-propoxy]-4-oxobutanoic acid & ++ & +++ & ++++ \\
\hline Monoavermectin-5-yl ester 4-\{2-[(4-methylphenyl)-amino]-2-oxoethoxy\}-4-oxobutanoic aci & +++ & +++ & ++++ \\
\hline Monoavermectin-5-yl ester 4-\{2-[(4-bromophenyl)-amino]-2-oxoethoxy $\}$-4-oxobutanoic acic & ++ & +++ & ++++ \\
\hline 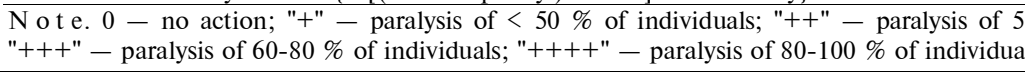 & $-60 \%$ & c. & viduals; \\
\hline
\end{tabular}

Antiparasitic activity parameters of the compounds we selected (see Table 1) evidenced a strong biocidal action: after a 30-minute exposure of oligochaetes to the $1.5 \%$ isopropanol solution of the tested compounds $(15 \mu \mathrm{g} / \mathrm{ml})$, half of the specimens lost their motor activity (see Table 1). Three of the tested compounds (5-O-succinyl-, 5-O-ethylsuccinyl- and 5,4"-di-O-succinyl avermectin B1) were selected for the acute toxicity evaluation.

$\mathrm{LD}_{50}$ of 5-O-succinyl avermectin $\mathrm{B} 1$ for mice was $37.85 \mathrm{mg} / \mathrm{kg}$, and $\mathrm{LD}_{100}$ was $70.35 \mathrm{mg} / \mathrm{kg}$, while of 5-O-succinyl avermectin B1 these were 41.37 and $74.27 \mathrm{mg} / \mathrm{kg}$, respectively, and of 5,4"-di-O-ethylsuccinyl avermectin B1 45.82 and $78.23 \mathrm{mg} / \mathrm{kg}$, respectively. These values are comparable to $\mathrm{LD}_{50}$ for currently used avermectin-based products, such as 20 and $30 \mathrm{mg} / \mathrm{kg}$ for abamectin and ivermectin [18].

The clinical manifestations of the toxic effects of the compounds were similar (muscle tremors, convulsions). All animals demonstrated discoordination of movements followed by strong depression: mice were lying, reactions to external stimuli were absent, and the death occurred within 20-30 min. Autopsy of the dead mice and the animals sacrificed at the end of the experiments showed no visible pathological changes. Therefore, according to the regulations of the 
State Standard GOST 12.1.007-76, these compounds can be regarded as substances of toxicity class II.

In vitro study of the influence on $\mathrm{GABA}_{\mathrm{A}}$-receptors showed that unlabeled SR 95531, the bromic 2-(3-carboxy prolyl)-3-amino-6- (4-methoxyphenyl)pyridazine (i.e. gabazine, a competitive antagonist of $\mathrm{GABA}_{\mathrm{A}}$-receptors), almost completely replaced [G- ${ }^{3} \mathrm{H}$ ]SR 95531 actively in the binding sites $\left(\mathrm{IC}_{50}\right.$ of $145 \mathrm{nM})$. Avermectin B1 under the same conditions inhibited the binding of [G- $\left.{ }^{3} \mathrm{H}\right] \mathrm{SR} 95531$ only partially $\left(\mathrm{I}_{\max } 22.0 \pm 1.2 \%\right.$ ) (Fig. 2, Table 2).

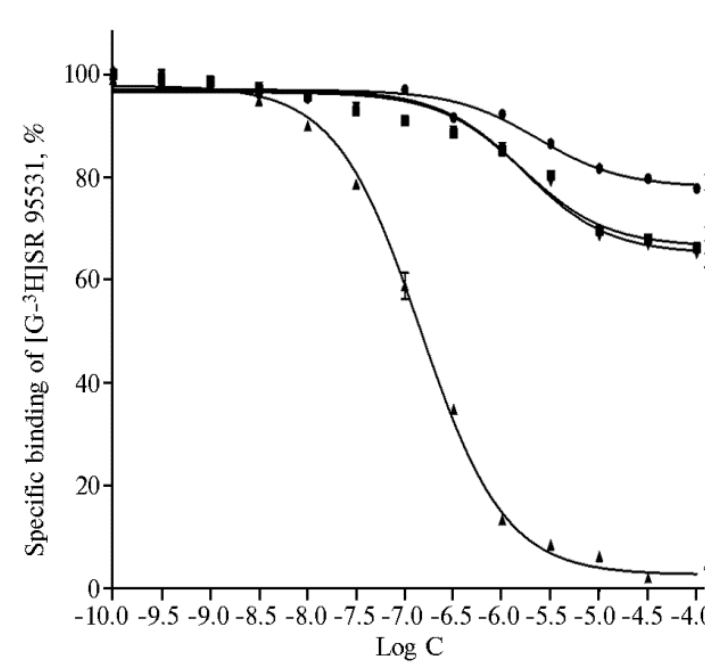

Fig. 2. Radioligand replacement with unlabelled SR 95531 and avermectins at in vitro binding $\left[\mathrm{G}^{-}{ }^{3} \mathrm{H}\right] \mathrm{SR} 95531$ to membranes of rat cerebral cortex: 1 - avermectin $\mathrm{B} 1 ; 2-$ ivermectin; $3-$ a hemisuccinate derivative of avermectin B1; 4 - SR 95531; Log C logarithm of the molar concentration of the compound.

A hemisuccinate of avermectin B1, i.e. an original derivative of avermectin B1, and ivermectin were shown to be more active inhibitors. Their $\mathrm{I}_{\max }$ increased by one third (up to $35.9 \pm 1.4$ and $33.5 \pm 1.4 \%$, respectively; $\mathrm{p}<0.05)$. However, all three studied substances had similar $\mathrm{IC}_{50}$ values in the micromolar range (Table 2).

2. Efficacy of avermectins in replacement of $[\mathrm{G}-3 \mathrm{H}] \mathrm{SR}$ 95531 specifically bond to membrane receptors of rat cerebral cortex $(m+\mathrm{SEM})$

\begin{tabular}{lc|c}
\hline \multicolumn{1}{c|}{ Compound } & $\mathrm{IC}_{50, \mu \mathrm{mol} / 1}$ & $\mathrm{I}_{\max } \%$ \\
\hline Avermectin B1 & $2.31 \pm 0.18$ & $22.0 \pm 1.2$ \\
Ivermectin & $1.61 \pm 0.14$ & $33.5 \pm 1.4$ \\
Hemisuccinate of avermectin B1 & $1.69 \pm 0.13$ & $35.9 \pm 1.4$
\end{tabular}

$\mathrm{N}$ ot e. $\mathrm{IC}_{50}$ - the concentration that causes $50 \%$ inhibition of specific radioligand binding; $\mathrm{I}_{\max }-$ the highest inhibition of ligand binding, which reflects the difference between the upper and lower plateau.

The results suggest that chemical modification of the avermectin B1 molecule significantly increased the competitive activity of the original compound, i.e. 5-O-succinyl avermectin, for the binding sites of [G${ }^{3} \mathrm{H}$ ]SR 95531 with GA-

$\mathrm{BA}_{\mathrm{A}}$-receptors. The use of labelled antibodies against GABA in the experiments with nematodes showed that 26 of 302 neurons in Caenorhabditis elegans were GABA-ergic [23], and genetic screening allowed to identify six genes which are required to perform the neural functions of GABA [24].

It is assumed that all three avermectins act as allosteric modulators of a specific $\mathrm{GABA}_{\mathrm{A}}$-receptor competitive ligand SR 95531 (gabazine) [25]. This is a GABA-derivative of arilaminopyridazine, which is a competitive receptor antagonist in mammals, whereas in invertebrates the substance SR 95103, i.e. 2-(3carboxy prolyl)-3-amino-4-methyl-6-phenylpyridazine, is more active [26]. Recent investigations in several laboratories have shown that the primary targets for macrocyclic lactones are glutamate-dependent chloride channels [4, 27]. These channels are not detected in mammals, but belong to the so-called family of Cys-loop channel receptors that includes GABA-, glycine, nicotine and serotonin-3 receptors. This, in particular, allowed using $\mathrm{GABA}_{\mathrm{A}}$-receptor of rat brain as a model to screen and study the mechanism of action of natural and semisynthetic avermectins.

Thus, the study of the biocidal action of a number of 5-O-substituted 
avermectins found that the $1.5 \%$ solution of 5-O-succinyl, 5-O-ethylsuccinyl and 5,4"-di-O-ethylsuccinyl avermectin B1 after a 60-minute exposure completely paralyzed oligochaetes. The $\mathrm{LD}_{50}$ values of these compounds, when administered intraperitoneally to mice at a dose of $37-47 \mathrm{mg} / \mathrm{kg}$, are comparable to or lower than those of the known analogues. Moreover, based on the effects according to State Standard GOST 12.1.007-76, these substances belong to toxicity class II, i.e. can be considered as promising antiparasitic agents.

\section{REFEREN C ES}

1. Ark hip ov I.A. Antigel'mintiki: farmakologiya i primenenie [Anthelmintics: pharmacology and use]. Moscow, 2009 (ISBN 978-5-85941-305-8) (in Russ.).

2. Dzhafarov M.Kh. Evolution in chemotherapy of human and animal helminthiases (review). Agricultural Biology, 2013, 4: 26-44 (doi: 10.15389/agrobiology.2013.4.26eng) (in Engl.).

3. N o b e lfo rs a m ling e n. The Nobel Assembly at Karolinska Institutet. The 2015 Nobel Prize in Physiology or Medicine. Available http://www.nobelprize.org/nobel_prizes/medi-cine/laureates/2015/press.pdf. No date.

4. Cam p bell W.C. History of avermectin and ivermectin, with notes on the history of other macrocyclic lactone antiparasitic agents. Curr. Pharm. Biotechnol., 2012, 13(6): 853-865 (doi: 10.2174/138920112800399095).

5. O m u r a S. Ivermectin: 25 years and still going strong. Int. J. Antimicrob. Agents, 2008, 31: 9198 (doi: 10.1016/j.ijantimicag.2007.08.023).

6. Pitterna T., Cassayre J., Huter O., Jung P.M., Maienfisch P., Kessa b i F.M., Q u a r a n t a L., T o b le r H. New ventures in the chemistry of avermectins. Bioorg. Med. Chem., 2009, 17: 4085-4095 (doi: 10.1016/j.bmc.2008.12.069).

7. D zhafarov M.Kh., Mirzaev M.N., Urazaev D.N., M a ks i mov V.I. Antiparasitic activity of adermectin and compounds of a steroid nature. Russian Agricultural Sciences, 2010, 36(2): 130-132 (doi: 10.3103/S1068367410020163).

8. D zhafarov M.Kh., M yrzaev M.N., Z avarsin I.V. Antiparasitic activity of famectin and some compounds of different chemical nature. Agricultural Biology, 2011, 2: 108-111. Available http://www.agrobiology.ru/2-2011dzhafarov-eng.html. No date (in Eng.).

9. R a y m o nd V., S a t t e 11 e D.B. Novel animal-health drug targets from ligand-gated chloride channels. Nat. Rev. Drug Discov., 2002, 1: 427-436 (doi: 10.1038/nrd821).

10. Estrada-Mondragon A., Lynch J.W. Functional characterization of ivermectin binding sites in $\alpha 1 \beta 2 \gamma 2$ LGABA(A) receptors. Front. Mol. Neurosci., 2015, 8: 55 (doi: 10.3389/fnmol.2015.00055).

11. Wolste nholme A.J., Rogers A.T. Glutamate-gated chloride channels and the mode of action of the avermectin/milbemycin anthelmintics. Parasitology, 2005, 131: S85-S95 (doi: 10.1017/S0031182005008218).

12. Lynagh T., Ly n c h J.W. Molecular mechanisms of Cys-loop ion channel receptor modulation by ivermectin. Front. Mol. Neurosci., 2012, 5: 60 (doi: 10.3389/fnmol.2012.00060).

13. Yoluk Ö., Brömstrup T., Bertac cin i E.J., Trude 11 J.R., Li ndahl E. Stabilization of the $\mathrm{GluCl}$ ligand-gated ion channel in the presence and absence of ivermectin. Biophys. J., 2013, 105: 640-647 (doi: 10.1016/j.bpj.2013.06.037).

14. Pang S., Qi S., Ran Z., Song X., Li X., Wang C., D ua n L. Synergistic effect of gamma-aminobutyric acid with avermectin on Bombyx mori. J. Food Agric. Environ., 2013, 11(1): 1022-1024.

15. Cobb R., B o e $\mathrm{ckh}$ A. Moxidectin: a review of chemistry, pharmacokinetics and use in horses. Parasites Vectors, 2009, 2(Suppl 2): S5 (doi: 10.1186/1756-3305-2-S2-S5).

16. Prichard R., M énez C., Lespi ne A. Moxidectin and the avermectins: Consanguinity but not identity. International Journal of Parasitology: Drugs and Drug Resistance, 2012, 2: 134153 (doi: 10.1016/j.ijpddr.2012.04.001).

17. Menez C., Sutra J.-F., Prichard R., Lespine A. Relative neurotoxicity of ivermectin and moxidectin in Mdrlab (2/2) mice and effects on mammalian GABA(A) channel activity. PLOS, 2012, 6(11): e1883 (doi: $10.1111 /$ jnc. 13644).

18. La n k s G.R., Gordo n L.R. Toxicology. In: Ivermectin and avermectin. W.C. Campbell (ed.). Springer-Verlag, NY, 1989: 89-112.

19. Chernoburova E.I., Lishchuk V.A., Ovchinnikov K.L., Kolobov A.V., $\mathrm{D} z$ h a farov M.Kh., Vas i levich F.I., Z a varzi n I.V. Izvestiya RAN. Seriya khimicheskaya, 2016, 12: 2965-2969 (in Russ.).

20. Mironov A.N., Bunyatyan N.D., Vasil'ev A.N., Verstakova O.L., Zhuravleva M.V., Lepakhin V.K., Korobov N.V., Merkulov V.A., Orekhov S.N., S a k a e va I.V., U t e s hev D.B., Yavorskii A.N. Rukovodstvo po provedeniyu doklinicheskikh issledovanii lekarstvennykh sredstv. Chast' I [Preclinical studies of drugs - guidelines. Part I]. Moscow, 2012: 13-25 (in Russ.). 
21. Hawkinson J.E., Acosta-Burruel M., Kimbrough C.L., Goodnough D.B., W o o d P.L. Steroid inhibition of $\left[{ }^{3} \mathrm{H}\right] \mathrm{SR} 95531$ binding to the $\mathrm{GABA}_{\mathrm{A}}$ recognition site. Eur. J. Pharmacol., 1996, 304: 141-146 (doi: 10.1016/0014-2999(96)00090-8).

22. Lowry O.H., Rosenbrough N.J., Farr A.L., Randall R.J. Protein measurement with the Folin phenol reagent. J. Biol. Chem., 1951, 193: 265-275.

23. S chuske K., B e g A.A., Jorge nse $\mathrm{n}$ E.M. The GABA nervous system in C. elegans. Trends Neurosci., 2004, 27: 407-414 (doi: 10.1016/j.tins.2004.05.005).

24. Wolste nholme A.J. Surviving in a toxic world. Science, 2012, 335: 545-546 (doi: 10.1126/science.1218166).

25. M a k s a y G. Differential effects of thiocyanate on the binding thermodynamics of bicuculline methiodide versus SR95531 (Gabazine) to the $\gamma$-aminobutyric acid receptor-ionophore complex. Biochem. Pharmacol., 1998, 56: 729-731 (doi: 10.1016/S0006-2952(98)00064-1).

26. Duittoz A.H., M a r i n R.J. Effects of the arylaminopyridazine-GABA derivatives, SR95103 and SR95531 on the Ascaris muscle GABA receptor: the relative potency of the antagonists in the Ascaris is different to that at vertebrate GABAa receptors. Comp. Biochem. Physiol., 1991, 98C: 417-422 (doi: 10.1016/0742-8413(91)90227-K).

27. Nakao T., B a nba Sh., Hirase K. Comparison between the modes of action of novel meta-diamide and macrocyclic lactone insecticides on the RDL GABA receptor. Pestic. Biochem. Phys., 2015, 120: 101-108 (doi: 10.1016/j.pestbp.2014.09.011).

\section{Events \\ BACTERIOPHAGE 2017}

(17-19 January 2017, online event, United Kingdom)

Organization: Euroscicon

Subdisciplines: biology, microbiology, molecular biology, biochemistry, medicine, biotechnology, virology

This is the FIRST live streamed only, three day professional conference discussing bacteriophages. This annual event will discuss emerging research relating to bacteriophage structure and mechanism of action, and their application in medical and industrial biotechnologies.

As one of the most abundant biological entities on earth, bacteriophages are major drivers of bacterial adaptive evolution through the predator-prey roles of the phage-bacterium interaction and through the adaptive impacts of lysogeny and lysogenic conversion. Bacteriophage biology underpins many biochemical reagents and technologies, indispensible for modern molecular biology, and phages continue to be exploited in several areas of biotechnology, including diagnostics, prophylaxis and other aspects of food microbiology. Furthermore, the use of bacteriophages as natural alternatives to antibiotics (known as phage therapy) are of increasing interest for the treatment of human and animal disease in the face of rising levels of antibiotic resistance. This meeting will bring together researchers working with phages across these disciplines to encourage collaboration and knowledge sharing. This event is aimed at those interested in the biology of bacteriophages and their applications in biotechnology, including research scientists, academics and pharmaceutical professionals.

Contacts: http://lifescienceevents.com/phage2017/

Information: http://www.globaleventslist.elsevier.com/events/2017/01/bacteriophage-2017/ 